\title{
EDUCAÇÃO E MODERNIZAÇÃO EM MINAS GERAIS: PROPOSTAS REFORMISTAS NA AÇẨO CONSERVADORA (1926-1930)
}

\author{
Pâmela Faria Oliveira \\ Universidade Federal de Uberlândia, Brasil. \\ Carlos Henrique de Carvalho \\ Universidade Federal de Uberlândia, Brasil.
}

$\cos 80$

\begin{abstract}
Resumo
Dentre as mudanças que marcaram a modernização do Brasil, a educação ocupou lugar central na dimensão intelectual e política do processo modernizante. Nesse sentido, este texto busca problematizar as relações entre educação e modernidade, sobretudo sua condição de índice de modernização em Minas Gerais na primeira metade do século 20. Para tanto, especulamos o discurso dos idealizadores da Reforma Educacional Francisco Campos a fim de reconhecer traços do ideário modernizante e progressista e vínculos com os interesses da elite oligárquica então predominante na política mineira. Os procedimentos metodológicos incluíram pesquisa bibliográfica, para a contextualização conceitual e histórica, bem como leitura dos discursos de Antônio Carlos e Francisco Campos.

Palavras-chave: Reforma Francisco Campos, progresso, oligarquia, moderno.
\end{abstract}

\section{EDUCATION AND MODERNIZATION IN MINAS GERAIS: REFORM PROPOSALS CONSERVATIVE IN ACTION (1926-1930)}

\begin{abstract}
Education played a central role in the intellectual and political dimension of the process of modernization in Brazil. This text focuses on this role by discussing the relationship between education and modernity, above its condition of an index of modernization in the state of Minas Gerais in the first half of the twentieth century. To do so, we analyze governor Antônio Carlos and his secretary Francisco Campos' discourses underlying their influent education reform, which is supposed to convey traces of progress and bonds with the local oligarchy's interests. Methodological procedures included bibliographical research to contextualize conceptually and historically our discussion and analytical reading of extracts of these politicians' official discourses. Key-words: Francisco Campos Reform, progress, oligarchy, modern.
\end{abstract}




\section{LA EDUCACIÓN Y LA MODERNIZACIÓN EN MINAS: PROPUESTAS \\ DE REFORMA CONSERVADORA EN ACCIÓN (1926-1930)}

Resumen

Entre los cambios que marcaron la modernización de Brasil, la educación ocupa un lugar central en la dimensión intelectual y política del proceso de modernización. Por lo tanto, este texto busca problematizar la relación entre la educación y la modernidad, en especial su índice de condición de la modernización en Minas Gerais en la primera mitad del siglo 20. Para ello, especulan que el discurso de los creadores de la Reforma Educativa Francisco Campos para reconocer las huellas de la modernización y las ideas progresistas y enlaces a los intereses de la elite oligárquica en la política minera vigente a continuación. Los procedimientos metodológicos incluyen la literatura para el contexto conceptual e histórico, así como la lectura de los discursos de Antonio Carlos y Francisco Campos.

Palabras-clave: Reforma Francisco Campos, oligarquía, moderno.

\section{ÉDUCATION ET LA MODERNISATION EN MINAS: PROPOSITIONS DE REFORME CONSERVATEUR EN ACTION (1926-1930)}

\section{Résumé}

Parmi les changements qui ont marqué la modernisation du Brésil, de l'éducation occupe une place centrale dans la dimension intellectuelle et politique du processus de modernisation. Ainsi, ce texte vise à problématiser la relation entre l'éducation et de la modernité, en particulier son indice de l'état de la modernisation dans le Minas Gerais dans la première moitié du 20 e siècle. Pour cela, nous nous interrogeons le discours des créateurs de la réforme de l'éducation Campos Francisco à reconnaître les traces de la modernisation et des idées progressistes et des liens vers les intérêts de l'élite oligarchique dans la politique, puis l'exploitation minière en vigueur. Les procédures méthodologiques incluent la littérature pour le contexte conceptuel et historique ainsi que la lecture des discours d'Antonio Carlos et Francisco Campos.

Mots-clé: Réforme Francisco Campos, oligarchie, moderne. 


\section{Introdução}

- ste artigo tem como objetivo analisar as relações entre a educação e a política de modernização no Estado de Minas Gerais, durante a implementação da Reforma Francisco Campos (1927-1928). Esta reforma foi elaborada num contexto histórico, a década de 1920, considerado de efervescência ideológica e de inquietação social.

Era um momento em que os projetos político-governamentais tinham de lidar com problemas como o analfabetismo; chaga responsável pelo atraso do país que devia ser extirpada, porque desorganizava o mercado criado pela produção capitalista que dava seus passos iniciais com a industrialização. Era urgente, pois, "organizar a instrução primária em moldes simples e concisos, de modo a facilitar e incrementar a sua intensa difusão" (Campos, 1930, p. 71). Ou seja, à escola cabia criar um tipo de cidadão despido do analfabetismo que, na visão das elites, trazia resistência ao progresso. Essa ideia de educar para progredir ecoava entre os líderes da política mineira, tendo em Francisco Campos e Antônio Carlos seus principais representantes à época, pois assumiam boa parte do ideário republicano, que projetava para a educação a função de promover o progresso e modernização do país, em particular do Estado de Minas Gerais.

Uma vez à frente do executivo mineiro, Campos e Antônio Carlos iniciaram algumas ações no sentido de reformar a realidade educacional mineira. O problema da educação foi alçado à categoria de um dos principais assuntos presentes nos discursos presidenciais proferidos por Antônio Carlos e Francisco Campos nos anos de 1927 à 1930. Esta centralidade dada à educação culminou com a reforma educacional do final dos anos de 1920, cujo objetivo, nas palavras de Francisco Campos, era "invadir" as escolas e perturbar "sua ordem, e pratica, os seus processos, o seu mecanismo, os seus habitos, a sua paz, a sua preguiça exigindo-lhes que se adaptem ás necessidades do mundo contemporaneo, aos imperativos de sua sciencia, da sua indústria, do seu trabalho e da sua cultura" (Campos, 1930, p. 60).

Nesse caso, estaria tal reforma alinhada a esse pensamento republicano? Com a ideia de educação como motor do progresso do país? Se sim, como tal alinhamento se materializou no discurso da reforma, isto é, nas palavras de quem a idealizou? Não seria essa preocupação com a educação no país uma resposta para acudir a situação de emergência criada por um liberalismo à brasileira - elevar o país a condição nação desenvolvida? Isto é, buscar o progresso com respaldo em ideias e ideários que supunham romper com a tradição - abraçar novos hábitos e costumes, desprezar o passado - mas sem quebrar a ordem oligárquica vigente, sem abandonar o conservadorismo? Eis as questões que buscamos refletir neste artigo, tendo como ancoradouro as propostas de Francisco Campos e Antônio Carlos para a educação. Analisamos seus discursos para tentar reconhecer traços indicativos de vínculos deles com os interesses da oligarquia, que dominou a política mineira até então.

\section{O ideário liberal no Brasil}

No Brasil, o ideário do Estado liberal penetrou, segundo Paim (1998), na voz de intelectuais que foram estudar em países europeus e nos Estados Unidos. Proclamada a República, a doutrina liberal se consolidou graças à intelectualidade, que a incorporou em sua discussão sobre mudanças. Esse autor afirma que um defensor convicto dos ideais 
liberais na Primeira República foi Rui Barbosa, cujas campanhas presidenciais de 1910 e 1919 apresentaram plataformas permeadas pelo pensamento liberal numa tentativa de estruturar o liberalismo como orientação da opinião nacional. Conforme Machado (2009), Rui Barbosa divulgou o projeto de modernização e se envolveu na mudança do trabalho escravo para o livre, da Monarquia para a República e da economia agrária para a industrial. Ainda segundo esse autor, modernizar, para Rui Barbosa, significava, sobretudo, educar o povo.

Mas, embora ele reconhecesse a educação como fator de desenvolvimento, progresso e liberdade, Machado (2009) afirma que progredir ia além da criação de condições materiais: significava manter a ordem necessária à sociedade burguesa. Assim, os traços liberais em Rui Barbosa não anulam, em sua obra, a força do espírito de uma época e de uma sociedade que aspirava à modernização, porém, mantendo a estratificação social.

Segundo Paim (1998), o liberalismo foi mais fértil na década de 1920, quando muitos movimentos contestatórios surgiram, o capitalismo deu sinais de expansão e a sociedade foi instada a participar mais da vida pública mediante o voto. Todavia, a Constituição de 1891 restringiu o direito de votar ${ }^{1}$ e essa restrição, sobretudo ao voto popular, indica um liberalismo conservador e contraditório: a defesa em prol de uma participação maior da sociedade na vida pública ignorava que a maioria expressiva da população estava legalmente alijada do direito de votar.

Assim, se o liberalismo se comprometia com a consolidação e o desenvolvimento de instituições do sistema representativo e o direito de votar, democratizar o sufrágio, segundo Paim (2000), tornou-se um desafio para doutrina liberal no século 20 , afinal, em seus primórdios, esta não se comprometia com o ideal de democracia. Seu propósito era frear e limitar o poder absoluto do monarca. Nessa ótica, a democratização via sufrágio distorceu o ideário liberal. Para Paim (2000, p. 132), os liberais de países como o Brasil "são instados a reconhecer que as tradições culturais predominantes lhes são desfavoráveis. Sem enfrentar essa questão, dificilmente serão capazes de formular políticas mobilizadoras, aptas a contribuir para a consolidação e a subseqüente hegemonia das tradições liberais".

Com efeito, as classes dominantes na Primeira República, afirma Pinheiro (1997), tinham gostos e opiniões conservadoras, além de serem arraigadas ao status quo. Estrategicamente diziam querer a democracia, mas reproduziam a exclusão política do Império. O governo mineiro de Antônio Carlos e Francisco Campos não foi exceção, pois sua política de feição liberal, que defendia o direito de voto a todos, excluía muitos cidadãos. Paim (2000) explica isso assim: a representação política liberal, em geral, afirmava que, numa democracia, os cidadãos agem "principalmente para maximizar o seu interesse pessoal e sua renda. Os partidos políticos, por sua vez, formulam políticas para ganhar eleições e não o inverso, isto é, não ganham eleições para formular políticas" ( $p$.

\footnotetext{
1 “Art. 70 - São eleitores os cidadãos maiores de 21 anos que se alistarem na forma da lei. $\S 1^{\circ}$ - Não podem alistar-se eleitores para as eleições federais ou para as dos Estados: $1^{\circ}$ ) os mendigos; $2^{\circ}$ ) os analfabetos; $3^{\circ}$ ) as praças de pré, excetuados os alunos das escolas militares de ensino superior; $4^{\circ}$ ) os religiosos de ordens monásticas, companhias, congregações ou comunidades de qualquer denominação, sujeitas a voto de obediência, regra ou estatuto que importe a renúncia da liberdade Individual" (Brasil,
} 1891). 
114). Em outras palavras, o partido político deve catalisar interesses e reprimir intenções particulares que visassem a uma sobreposição ao interesse geral.

Embora, as ideias modernizantes que marcam a reforma educacional concebida por Francisco Campos e reiteradas pelo então presidente de Minas Gerais, Antônio Carlos, nos impeçam de incluí-los nessa elite oligárquica que travou a modernização do Estado, o mesmo não pode ser dito de sua condição de representantes políticos de tal elite, mesmo que isso fosse uma oposição à postura de liberais. Segundo Peixoto (1983), o presidente de Minas afirmou a importância do voto livre e secreto, assim como reiterou seu esforço para assegurar que esse direito fosse exercido com liberdade.

Caso se possa dizer que ideologicamente a campanha política de Antônio Carlos tenha configurado uma luta pró-liberdades públicas e tradições liberais e anti-Estado analfabeto, oligárquico e autoritário, mesmo que a oligarquia compusesse sua base política essencialmente, também pode ser dito que a bandeira liberal de campanha teve fins político-eleitoreiros, isto é, foi uma tentativa de angariar apoio popular citadino. Ora, $17 \%$ da população no período enfocado, como se vê na tabela 1, residia na cidade, logo defender os interesses desse povo era ignorar que $83 \%$ da população brasileira que era rural. Isso relativiza a bandeira liberalista sob qual Antônio Carlos se elegera dirigente do Estado.

Tabela 1

População residente por domicílio - 1900-2000.

\begin{tabular}{|c|c|c|c|c|c|}
\hline \multirow{2}{*}{ Ano } & \multicolumn{5}{|c|}{ População em milhões } \\
\cline { 2 - 6 } & Rural & $\%$ & Urbana & $\%$ & Total \\
\hline 1900 & 15.300 .000 & 90 & 1.700 .000 & 10 & 17.000 .000 \\
\hline 1920 & 27.500 .000 & 83 & 4.600 .000 & 17 & 32.100 .000 \\
\hline 1940 & 28.300 .000 & 68,1 & 12.900 .000 & 31,3 & 41.200 .000 \\
\hline 1950 & 33.200 .000 & 63,8 & 18.800 .000 & 36,2 & 52.000 .000 \\
\hline 1960 & 38.800 .000 & 55,5 & 31.300 .000 & 44,5 & 70.100 .000 \\
\hline 1970 & 41.100 .000 & 44,1 & 52.100 .000 & 55,9 & 93.200 .000 \\
\hline 1980 & 38.600 .000 & 32,5 & 80.400 .000 & 67,5 & 119.000 .000 \\
\hline 1991 & 35.800 .000 & 24,5 & 111.000 .000 & 75,5 & 146.800 .000 \\
\hline 2000 & 31.800 .000 & 18,7 & 138.000 .000 & 81,3 & 169.800 .000 \\
\hline
\end{tabular}

Fonte: IBGE, 2002.

Podemos perceber, nos discursos presidenciais de Antônio Carlos e Francisco Campos, a ausência de benfeitorias e discussões sobre a educação rural, mesmo que o Estado fosse classificado como terceiro em termos de valor de propriedades rurais estava atrás de São Paulo e Rio Grande do Sul.

Ainda seguindo a ótica liberal, Antônio Carlos e Francisco Campos queriam disseminar a educação primária pública e gratuita a toda a população de Minas. Conforme Paim (2000, p. 146), os educadores liberais tiveram papel central na assimilação do consenso de que a educação obrigatória seria capaz de "elevar os padrões de renda e eliminar a pobreza [...] à medida que o sistema representativo ganhou dimensão universal". Se assim o for, então convém entender um pouco das relações entre liberalismo e processo pedagógico nos anos 1920, sobretudo com a difusão do movimento da Escola Nova, importante para constituir o pensamento liberal no mundo e fundar teoricamente a educação para a cidadania. A educação liberal é, 
em primeiro lugar, a herdeira do sistema de ensino criado na Época Moderna pelas igrejas protestantes e que, no século passado, tornara-se uma incumbência das comunidades, conhecido pela denominação de educação popular. Essa transição das escolas confessionais para o sistema público deu lugar a um grande embate - de natureza teórica, mas envolvendo também encarniçada luta política -, que determinou pelo estabelecimento de uma legislação fixando o caráter do ensino oficial, de maneira que não interferisse na liberdade religiosa. Somente em nosso século este sistema de ensino foi batizado de forma adequada. Chamou-se de educação para a cidadania. (Paim, 2000, p. 137)

A influência do liberalismo na educação do Brasil veio, em especial, de Dewey, isto é, da Escola Nova, que pretendia, diz Paim (1998), levar a proposta liberal ao plano curricular-pedagógico e, assim, fazer surgir uma educação para a cidadania.

Ao apontar diferenças entre a educação tradicional e a progressiva, Dewey afirmou que a fundamentação teórica da primeira se baseia em informações e habilidades produzidas no passado e transmissíveis às novas gerações com certos padrões, os quais incluem "organização em horários, esquemas de classificação, avaliação, promoção, método de instrução, disciplina, o livro como objeto material essencial e a imposição às crianças dos padrões dos adultos". Por outro lado, "a educação proposta por Dewey cultivaria a "individualidade, a atividade livre, a aprendizagem pela experiência, o aproveitamento das oportunidades da vida presente próprias de um mundo em mudança" (Valdemarim, 2010, p. 78).

A defesa do movimento escolanovista mostrava uma visão de educação como instrumento apto a reformar e construir uma sociedade. Buscava-se, neste momento, romper com a educação dita tradicional e este desejo estava presente nos discursos de Antônio Carlos e Francisco Campos, ao defenderem que a escola,

para ser educativa, deve estar em continuidade com a vida social, de que se constitui em prolongamento e dependência, pois se destina a transmittir pela educação os processos sociaes em uso; mas, a escola, como instrumento educativo, não se limita apenas á transmissão passiva, senão que transmitte corrigindo, rectificando, aperfeiçoando e melhorando, de onde a sua influencia sobre a sociedade, cujas tendências e aspirações inculca ás creanças não sob a fórma vaga e impalpavel do ideal, senão sob a fórma de hábitos, costumes, regras de vida e disciplina da intelligencia e da vontade. (Campos, 1930, p. 14)

Nagle (2001) afirma que não havia indícios claros de um movimento liberal. Este ganharia contornos nítidos em meados dos anos 1920, quando o escolanovismo entrou na fase da difusão de seu ideário:

Nesta fase se encontra a difusão sistemática dos ideais da Escola Nova, período em que a literatura educacional, além de se expandir, se altera qualitativamente, dada a freqüência com que se publicam trabalhos sobre assuntos referentes à "nova pedagogia". Ao mesmo tempo se difundem as novas idéias e aparece a nova literatura, se processa a infiltração do escolanovismo no movimento reformista da instrução pública: na década de 1920 tenta-se, pela primeira vez, realizar o novo modo de estruturação das instituições escolares. (p. 310) 
Como produto da década de 1920 e da lavra de dois políticos de extração liberal, a reforma Francisco Campos não podia fugir a esse ideário. Isso fica patente na proposta de mudança que coerente com a efervescência ideológica e a inquietação social ante um descompasso entre forças sociais dominantes, a oligarquia, e forças sociais emergentes, a modernização. Se for correto que o programa de governo de Antônio Carlos e Francisco Campos buscava suprir demandas sociais como a educação para todos, seguindo a bandeira liberal, também é correto dizer que essa deixava entrever contradição, sobretudo se considerarmos que Campos se tornou ministro da Justiça do Estado Novo, contrário às ideias liberalistas defendidas por ele quando estava envolvido com o governo mineiro. Mais que isso, essa contradição possibilita aventar a ideia de que as demandas que tentaram não eram aquelas das forças emergentes, mas das forças conservadoras: as elites mineiras.

O quadro político brasileiro, sobretudo em Minas Gerais, tinha uma feição complexa porque traduzia a vontade das oligarquias estaduais de conservar privilégios lançando mão de estratégias políticas espúrias. Tais estratégias ganhavam forma na mão de políticos que, não raro, provinham da classe oligárquica e que compunham a elite intelectual do país. A presença de Francisco Campos no governo Antônio Carlos, como político e intelectual, pode ser tomada como exemplo da presença oligárquica numa proposta liberal de governo e de educação.

Subjacente a essa presença estava o pressuposto de que os intelectuais brasileiros estavam aptos a solucionar problemas sociais graves, como o analfabetismo e a suposta ignorância do povo. Entregaram-se à ação política como se tivessem qualificação e preparo especial para fazê-lo. Muitos se tornaram protagonistas políticos centrais, como Francisco Campos. Uma vez na elite dirigente, acreditavam que viam a realidade brasileira como ninguém: conheciam os mecanismos sociais e os interesses profundos de grupos distintos, dão se posicionavam como mediadores indispensáveis às classes. Segundo Pécaut (1990), com o processo de decadência do Estado oligárquico, os intelectuais, originários de famílias dessa estirpe, buscaram se projetar na política ante o temor de perder o status e o estilo de vida das elites ditas cultas. A política era a oportunidade de terem uma ocupação profissional que lhes daria visibilidade pública e preservaria sua posição nas elites dirigentes. Essa estratégia marcou o período posterior à passagem do Império para a República, quando gerações sucessivas de políticosintelectuais e intelectuais-políticos abraçaram as causas do povo em prol de um projeto nacional e invocaram a realidade nacional.

Todavia, para Pécaut (1990), tal engajamento soava falso. Como burgueses de origem, os intelectuais-políticos não se desvinculavam de seus interesses específicos nem agiam para "fazer prevalecer valores de justiça. Apenas o faziam porque o intelectual tinha de estar à altura da construção da nação, portador que era da identidade nacional e, além disso, detentor do saber relativo às leis da evolução histórica" (Ibid., p. 6). Para ele, os intelectuais justificavam sua presença na política porque o povo era ignorante e classes sociais se formavam; dada a ignorância do povo, seria fácil lhe incutir ideologias, enfim, a ideologia permitia que fossem da elite quando necessário e do povo quando conviesse. 


\section{Modernização em Minas Gerais}

A ideia de contradição se associa, também, à modernização de Minas Gerais, onde esse processo foi gradativo e multifacetado. Os entraves centrais à difusão de elementos modernizantes foram o conservadorismo e a hierarquização. Os valores da sociedade mineira exposta ao processo modernizante eram os valores de uma sociedade agrária e classista, cuja manutenção da condição de rico e de pobre legitimava e perpetuava a ordem social, além de concentrar o poder mercantil, agrícola e político nas mãos de grupos fechados ligados por parentesco (Wirth, 1982). Arraigada à tradição, essa sociedade era composta por uma população de feição rural e tinha uma economia de base agrária, voltada ao mercado interno, e uma organização política ainda oligárquica. Nesse contexto socioeconômico, a assimilação dos elementos modernizadores foi desuniforme e pouco incisiva. Noutros termos, esbarrou na força da ordem oligárquica.

Segundo Wirth (1982), Minas Gerais apresentava muitos contrastes: tinha relações complexas com regiões mais ricas e dinâmicas do Sul, porém, mantinha vínculos fortes com regiões mais dependentes do Norte. Além de energia e recursos naturais, pela localização geográfica, era uma via de passagem importante econômica e socialmente, com potencial industrial, de transporte e de renda. À força política, os mineiros dirigiram o país de 1889 a 1930, junto com paulistas e gaúchos, equivalia à fraqueza socioeconômica. No dizer desse autor, a formação das cidades mineiras principia na década de 1920, com o êxodo da população rural atraída, especialmente, pela oferta de trabalho. Contudo, mesmo tendo cinemas, farmácias, escolas e centros de saúde pública, a maior parte das cidades pequenas mantinha vínculos fortes com a vida no meio rural, pois ainda era o produto da produção rural que mantinha a economia delas.

Todavia, assim como é plausível reconhecer indícios de modernização no Brasil já na segunda metade do século 19, Antonio Paula (2000) considera que o Estado de Minas Gerais nasceu moderno. Prova disso seriam o crescimento da urbanidade e uma estrutura de ocupação diversificada, que intensificou o comércio interno graças à mineração aurífera, à atividade manufatureira e à formação da indústria. Segundo Paula (2000), a urbanização trouxe outro padrão de sociabilidade, novas relações políticas e econômicas, novos costumes, novas sensibilidades e novas mentalidades. As cidades viriam superar a feição rural da sociedade mineira como indício-chave da modernização.

Se o processo de urbanização e a entrada do Estado na era moderna tiveram como marco central o surgimento da capital Belo Horizonte, uma cidade planejada (Wirth, 1982), a consolidação da vida urbana foi reforçada por outro símbolo-chave da modernização: o surgimento da indústria. Além da produção de bens de consumo e do desenvolvimento de técnicas de produção, a industrialização motivou a reorganização espacial urbana, a disciplina e o controle, a divisão do trabalho, a renda e o consumo. $\mathrm{E}$ mais: impôs a discriminação e exclusão das classes inferiorizadas. Por isso se diz que a modernização em Minas Gerais não conseguiu suprir uma das promessas do processo modernizante: estabelecer "relações econômicas capazes de produzir a melhoria das condições de vida do conjunto da população" (Ibid., p. 81). Noutros termos, a modernização à mineira não enfraqueceu o tradicionalismo e conservadorismo da elite, ainda "localista e isenta de crises de identificação e função" (Ibid., p. 147).

Não se pode negar, porém, que a modernização do Estado, que despontava na década 1920, não tenha trazido novas concepções, a exemplo das formas de conceber a 
educação, que passou a ser vista ponte para o progresso. Era preciso educar as massas e "transformá-las em outros tantos instrumentos de produção de bens econômicos" (Campos, 1930, p. 71). Afinal, mesmo que a instrução pública preocupasse o governo provincial, isso não bastou para reduzir os índices de analfabetismo: chaga cuja extirpação supunha incluir a escola na reorganização do espaço urbano motivada pela industrialização. Dito de outro modo, era preciso reformar o sistema de instrução pública, visto que da educação do povo dependia o progresso do Estado e do país.

\section{Projeto político e educacional para Minas Gerais}

Até 1920, diz Wirth (1982), Minas Gerais, que tinha liderança econômica, demográfica e política, foi superado pelo Estado de São Paulo, em função de apresentar logo no início da República uma economia mais diversificada, isto é, prometia oportunidades variadas, diferentemente das práticas conservadoras da oligarquia mineira. Como o Estado padecia de doenças epidêmicas em algumas localidades, supõe-se que a saúde pública fosse precária, assim como a educação - a taxa de analfabetismo era alta. Esses fatores, por si só, diziam muito da falta de progresso e modernização e estimularam a migração.

Ainda na visão de Wirth, numa economia de base agrícola e pastoril, a industrialização atendia ao mercado doméstico e empregava pouca gente. A isso se aliam uma produção cafeeira irregular e um sistema viário e transporte deficiente, que reforçava a dependência de São Paulo e do Rio Grande do Sul, Estados com os quais Minas Gerais tinha relações econômicas de dependência. Assim, resolver os problemas supunha construir estradas de ferro e estimular o mercado interno. Todavia, mesmo a construção de ferrovias e abertura de rodovias entre 1870 e 1930 não integrou suficientemente as regiões do Estado.

Com efeito, a fraqueza e desorganização do mercado mineiro compuseram a formulação de projetos políticos à época, pois foram associadas com o analfabetismo. Assim, a reforma educacional de Antônio Carlos e Francisco Campos tinha respaldo não só em argumentos do contexto nacional, mas também em necessidades criadas, sobretudo, pela elite mineira para acelerar o desenvolvimento e a modernização do Estado.

Como tentamos contextualizar até aqui, a educação foi tomada como indício de modernização de Minas Gerais. Mas a assunção das questões educacionais como programa político tinha outros interesses que não o educar o povo propriamente dito. Na proporção que a economia capitalista assumia as rédeas do desenvolvimento, políticos e líderes empresariais pouco afeitos à educação passaram a expressar preocupação e disposição para agir em prol dessa faceta da sociedade. A defesa da qualidade e da difusão da instrução primária seguiu a lógica da relação custo-benefício: formar e manter uma força de trabalho estável e qualificada para o futuro: a industrialização.

Isso sugere que o interesse pela educação se voltava à instrução da população urbana. Do contrário, o projeto político de Antônio Carlos teria previsto uma reforma que mudasse, também, a feição da educação rural em Minas Gerais. A reforma propôs uma modificação no ensino rural: "até á reforma, o curso nas escolas ruraes era apenas de dois annos. [...] [Após a reforma] o curso nas escolas ruraes passou a ser de tres annos, o que, certamente, contribuirá para melhorar o ensino" (Minas Gerais, 1928, s. p.). Pode-se 
aventar a possibilidade de que esse desdém pelo ensino no campo se explique pela ideia, construída e apropriada pela sociedade, de que o meio rural é atrasado e tradicional, isto é, antítese da vida urbana, da vida moderna, do progresso (Paim, 1984). Nessa ótica, ao ser associada com a educação que deveria democratizar o país, a modernização de Minas Gerais ajudou a esconder problemas mais graves de uma sociedade cuja população era, a maioria, habitante do campo:

A ênfase na educação primária não anulou interesse de Antônio Carlos e Francisco Campos por outros níveis educacionais como o ensino superior, embora investimento tenha sido quase imperceptível. A lei n. 956, de 7 de setembro de 1927, creou a Universidade de Minas Geraes. A mesma lei auctorizou o Governo a constituir patrimonios, cujos rendimentos, respectivamente, de 200:000\$000, 350:000\$, 600:000\$000 e 50:000\$000, auxiliem a manutenção da Faculdade de Direito, da Escola de Engenharia, da Faculdade de Medicina e da Faculdade de Odontologia e Pharmacia de Bello Horizonte, que se reuniram para constituir a Universidade de Minas Geraes. O decreto n. 7.921, de 22 de setembro do mesmo anno, approvou o Regulamento da Universidade, que, considerada fundação, com personalidade jurídica de direito privado, objectiva o desenvolvimento dos institutos que lhe são incorporados, o estímulo da cultura scientífica, o aperfeiçoamento do ensino e, em summa, o engrandecimento intellectual e moral do Estado de Minas e do Brasil. (Minas Gerais, 1928, p. 47)

Segundo Nagle (2001), a elite nacional pedia uma formação superior, por isso era necessário estruturar uma universidade que pudesse formar a elite apta a governar o país. Atentos a essa demanda, Campos e Andrada criaram a Universidade de Minas Gerais $^{2}$, cuja sede seria o prédio da Faculdade de Direito, influente na formação da intelectualidade e da política mineiras. Assim, criar uma universidade cumpria parte de um programa político coerente com os interesses das oligarquias: além de escolas normais e secundárias para alimentar os valores humanistas ocidentais, havia escolas superiores para elite. Para a massa, a escola primária, como forma de suprir uma demanda social que poderia garantir não só votos, mas também eleitorado fiel.

A permanência no governo supunha outras condições, a exemplo de laços que deviam ser firmados com grupos sociais distintos, úteis à influência do governo de Antônio Carlos. Dentre esses grupos está o professorado, convocado a participar do Congresso de Ensino Primário ${ }^{3}$ para conhecer as ideias educacionais e, uma vez cientes destas, ser cooptado a defender o projeto político-educacional modernizante do governo, como foi

\footnotetext{
2 "A lei n. 956, de 7 de setembro de 1927, creou a Universidade de Minas Geraes. A mesma lei auctorizou o Governo a constituir patrimonios, cujos rendimentos, respectivamente, de 200:000\$000, 350:000\$, 600:000\$000 e 50:000\$000, auxiliem a manutenção da Faculdade de Direito, da Escola de Engenharia, da Faculdade de Medicina e da Faculdade de Odontologia e Pharmacia de Bello Horizonte, que se reuniram para constituir a Universidade de Minas Geraes. O decreto n. 7.921, de 22 de setembro do mesmo anno, approvou o Regulamento da Universidade, que, considerada fundação, com personalidade jurídica de direito privado, objectiva o desenvolvimento dos institutos que the são incorporados, o estímulo da cultura scientífica, o aperfeiçoamento do ensino e, em summa, o engrandecimento intellectual e moral do Estado de Minas e do Brasil" (Minas Gerais, 1928).

3 "Atendendo a convocação do governo, reuniu-se, nesta Capital, em maio próximo findo, o Congresso de Ensino Primário, cujas luzes, devendo provir de pessoal experimentado, pareceram úteis à administração, para o fim da reforma que planejo, e já exposta, em linhas gerais, por mim e pelo Secretário do Interior, em vários documentos públicos. As resoluções do congresso, em sua maioria merecedoras de acatamento, terão o devido apreço na elaboração do regulamento que, sobre esse importante assunto, será, dentro em pouco, expedido" (Minas Gerais, 1927).
} 
manifestado por Antônio Carlos Ribeiro de Andrade, em ato presidencial sobre o apoio recebido dos professores primários depois do Congresso de Ensino Primário, realizado em Belo Horizonte:

Atendendo a convocação do governo, reuniu-se, nesta Capital, em maio próximo findo, o Congresso de Ensino Primário, cujas luzes, devendo provir de pessoal experimentado, pareceram úteis à administração, para o fim da reforma que planejo, e já exposta, em linhas gerais, por mim e pelo Secretário do Interior, em vários documentos públicos. As resoluções do congresso, em sua maioria merecedoras de acatamento, terão o devido apreço na elaboração do regulamento que, sobre esse importante assunto, será, dentro em pouco, expedido. (Minas Gerais, 1927b)

Assim, Antônio Carlos e Francisco Campos divulgaram seu projeto político com apoio da densa e compacta massa de analfabetos e do professorado, tido como central à concretização da reforma educacional.

\section{Reforma Francisco Campos: o projeto modernizador mineiro}

Com efeito, reformas da educação estiveram na pauta da política educacional mineira nas primeiras décadas do século passado: em 1906 (João Pinheiro) ${ }^{4}$, em 1910 (Wenceslau Brás) $^{5}$, em 1910-11 (Bueno Brandão) ${ }^{6}$, em 1915-16 (Delfin Moreira) ${ }^{7}$, em 1924-26 (Mello Viana) ${ }^{8}$, além das modificações feitas durante o governo Artur Bernardes $(1921-24)^{9}$. Essas iniciativas reformistas antecederam a reforma que se tornaria a mais importante: a Reforma Educacional Francisco Campos, levada a efeito pelo governador Antônio Carlos Ribeiro de Andrada ${ }^{10}$ e seu secretário de Interior, Francisco Luís da Silva Campos. Mais ampla que a reforma de 1925, a de Francisco Campos foi anunciada na festa cívica do primeiro centenário do ensino primário, da qual participaram seis mil

\footnotetext{
${ }^{4}$ Criou o sistema de grupos escolares, reformulou os níveis primário, normal e superior; começou a pensar na criação de escola normal modelo, aprovou o regimento interno dos grupos escolares e reforçou a fiscalização, prescreveu os métodos intuitivo e prático, dentre outras ações. Contudo, não inovou no ensino normal, que continuou a ser simples e resumido.

${ }^{5}$ Aprovou o regulamento da reorganização escolar, na qual uma mudança-chave ocorreu na duração do curso normal de três anos para quatro, além de classificar a escola normal de Belo Horizonte como modelo.
}

6 Pouco distinta da reforma João Pinheiro, determinou normas ao pré-primário, primário e normal, criou escolas rurais, previu escolas dominicais, fixou diretrizes para exercícios físicos e, sobretudo, estabeleceu a primeira escola infantil.

${ }^{7}$ Sem fazer mudanças fundamentais, fixou instruções ao ensino da escola infantil.

${ }^{8}$ Estipulou gratificação especial a docentes normalistas, alinhou muitas escolas normais à Escola Normal Modelo e criou numerosos grupos escolares; também aprovou o Regulamento do Ensino nas Escolas Normais e programas de ensino para o jardim de infância e para cursos complementares, primários agrícolas e ensino primário.

${ }^{9}$ Governador, Artur Bernardes; secretário do Interior, Afonso Pena Júnior. Como mudanças mais importantes, essa reforma criou escolas rurais, nomeou professores de ensino primário e facultou o ensino da religião católica; os quesitos organização, metodologia e programas não foram revistos, embora tenha atido ao ensino universitário com a criação da Escola Superior de Agricultura e Veterinária.

${ }_{10}$ Natural de Barbacena (MG), estudou segundo métodos pedagógicos contrários ao castigo físico e favoráveis à persuasão e ao apelo à dignidade como atitudes mais aptas à formação de cidadãos dignos. $\mathrm{Na}$ faculdade de Direito de São Paulo deu vazão à vocação e ao desejo de participar da vida política, entusiasmado pela causa republicana e pelo liberalismo clássico. Sua preocupação com o ensino escolar foi tal que a educação se tornou um compromisso expressivo de sua plataforma de governo. Ciente da situação precária da educação, ao assumir a presidência de Minas focou na melhoria dos níveis primário e normal. Também reiterava o pressuposto de que o aprimoramento do ensino primário era condição direta para o progresso social e econômico.

\begin{tabular}{l|l} 
Hist. Educ. [online] & Porto Alegre
\end{tabular}


pessoas, com crianças cantando o hino, desfile e lançamento de edição especial da Revista de Ensino, órgão oficial da diretoria de Instrução Pública (Vidal, 2009).

Segundo Peixoto (1983), a reforma de Campos se preocupou com a face técnicopedagógica da escola, assim como com uma renovação escolar coerente, diria Abreu (2001, p. 999), com os "postulados da escola nova", então difundidos no país na voz de educadores como "Anísio Teixeira e Fernando de Azevedo" no pós-Primeira Guerra Mundial.

Como reiteramos até aqui, se modernizar significava romper com a tradição do passado, podemos supor que os postulados da Escola Nova representavam a modernização, pois propuseram uma quebra da tradição no ensino, isto é, do que Campos, segundo Abreu (2001), via como retórico e ornamental, próprio para formar elites; logo, a escola nova, supostamente, opunha-se a isso, uma vez que "deveria ensinar a pensar, a inventar e a criar soluções para a multiplicidade de novos problemas da complexa vida moderna" (p. 999). Para Campos, ainda segundo esse autor, a orientação e o incremento da instrução primária não poderiam fazer eleitores se não os tivessem feito cidadãos antes, mediante uma educação que formasse homens e orientasse a inteligência. Para Campos, o futuro das instituições democráticas dependia dessa formação. Dito de outro modo, a Escola Nova poderia embasar a formação de cidadãos aptos a participar da sociedade moderna pelo voto: a democracia como participação de todos.

Se essa reforma compunha o processo modernizador de Minas Gerais, estaria ela isenta de contradições? O discurso pró-modernização de Campos não replicava as contradições desse processo em Minas? Teria ele esbarrado na estrutura oligárquica do Estado? Vejamos como se apresenta o discurso do Francisco Campos, secretário dos Negócios do Interior de Minas Gerais. Cremos que aí seja possível reconhecer ideais de moderno e modernização relacionáveis com a proposta educacional patente na reforma da educação que ele elaborou.

O livro Pela civilização mineira (1930), reúne discursos de Campos publicados em documentos da Secretaria dos Negócios do Interior que, talvez, permitam encontrar uma via de compreensão e interpretação da reforma de ensino elaborada por ele e levada a efeito no governo de Antônio Carlos. Consideremos o trecho a seguir, que compõe o documento Exposição de motivos do novo regulamento do ensino primário - 14 de outubro de 1927 e dá pistas da visão geral que Campos tinha de educação escolar:

Si a escola, porém, pela educação, adapta a creança á vida social, fazendo-a assimilar a ordem intellectual e moral reinante, de que é um poderoso instrumento de conservação, ella, por sua vez, como órgão de aspirações e de ideaes, reage sobre a sociedade, a cujo serviço é destinada, introduzindo-lhe na circulação fermentos e reactivos que the provocam alterações e transformações profundas, agindo, quer immediatamente, por influencia directa, quer mediata e indirectamente, por intermédio dos futuros cidadãos, cuja intelligencia e cujo caracter receberam a marca da sua influencia, indelével por que impressa em metal ainda em via de resfriamento e de condensação e, por conseguinte, plástico e ceroso. (Campos, 1930, p. 13)

Essas palavras deixam entrever que a educação escolar reflete aspirações de cada época e sociedade, conserva a ordem intelectual e moral vigente e visa à adaptar a 
criança à vida social. Adaptar, nesse caso, sugere moldá-la à vida em sociedade, daí a comparação metafórica com a ideia de metal quente, isto é, pronto para ganhar formas mediante a manipulação esmerada, disciplinada e rigorosa do metalúrgico/professor.

O documento cita várias outras questões sugestivas de um ideal modernizador no discurso de Campos, dentre as quais: garantir cooperação entre escola e meio social, fazer valer a condição da escola como miniatura da sociedade, apontar a educação primária como algo que não prepara para a vida escolar, entender mais o desenvolvimento físico e psíquico da criança mediante a psicologia e biologia, recorrer a orientações e pensamentos novos acerca do processo de ensino e aprendizagem, introduzir o método Decroly, qualificar os programas de ensino e a formação docente reformando o ensino normal, inspecionar a parte técnica da educação, oferecer assistência escolar médica e odontológica, organizar o conselho superior de educação e o magistério em carreira regular, enfim, aparelhar e construir prédios escolares. Com efeito, o documento é abrangente, o que permite cogitar que, para Campos, melhorar a educação era fator central ao progresso de Minas Gerais.

Uma ideia central no discurso de Campos foi a de que qualificar a escola normal, diga-se prover formação docente pedagógica especializada. Talvez por isso "fiz seguir para os Estados Unidos um grupo de professores, para que ouvissem, por dois annos, os especialistas na matéria. Contratei na Suissa, França e Belgica, professores de nomeada para o aperfeiçoamento de nosso professorado" (Campos, 1930, p. 235). Na Exposição de motivos do regulamento do ensino normal - 20 de janeiro de 1928 ele advoga o papel central do professor e da presença de técnicos e psicólogos no ensino normal, assim como da biologia, higiene e psicologia educacional. O Discurso de installação do curso de aperfeiçoamento - 14 de junho de 1928, que trata do aperfeiçoamento docente, reforçou o conteúdo da exposição de motivos de 1928. Acrescente-se que esses dois documentos revelam uma aspiração à reforma do espírito, dos processos e da organização do ensino primário. Contudo, mais que renovar e readaptar a escola normal, era preciso rever

as exigências e a finalidade do ensino primário, os seus methodos, os seus processos e os seus programmas; uma larga e fecunda actividade prática e theorica tem-se exercido, infatigavelmente, na investigação dos seus termos, dos seus fins e dos coefficientes intellectuaes e moraes de sua organização; experiências, tentativas, reformas e projectos multiplicam-se, dia a dia, no sentido de approxima-lo cada vez mais das finalidades e exigências que lhe estão, visivelmente, a impor não apenas o estado actual, senão as formas virtuaes que tendem a revestir e definir a nossa cultura e, por conseguinte, a nossa concepção dos valores humanos. (Campos, 1930, p. 41)

Como se pode ler nessa passagem, renovar a educação se ajustava a necessidades maiores: aquelas da sociedade moderna. Eis porque a reforma tinha de ser profunda, mediante experiências, projetos e atividades práticas e teóricas que redundassem em métodos e técnicas para qualificar a educação, isto é, suprir os interesses da sociedade que se formava, diria Carvalho (1998, p. 169): "adequação dos costumes urbanos às exigências do trabalho industrial na ordem capitalista", na qual a escolarização poderia ser alternativa ao controle pela violência policial. Esse aprofundamento fica patente na defesa da presença das cadeiras de biologia e psicologia educacional: 
O estudo da biologia humana e de hygiene não podia deixar de integrar-se, como disciplina autônoma, no curso destinado á formação do professorado primário. A influencia dos pontos de vista biológicos sobre a educação, a necessidade do conhecimento das formas que actuam no crescimento physico e mental das creanças, dos fatores organicos que determinam as suas reacções, que o ensino da biologia humana não podia deixar de constituir uma parte das mais importantes do curso normal graduado. (Campos, 1930, p. 51)

Supostamente essas áreas poderiam proporcionar um conhecimento maior da fisiologia e da intelecção da criança. Mais que isso, traduziam uma pedagogia moderna em que

a ciência suprema do mestre residia no conhecimento do discípulo no método tradicional, os alunos se dobravam a rígidas prescrições gerais; no método moderno, o ensinamento é que se adaptava "ao discípulo como centro do mundo escolar. Tal adaptação deveria alicerçar-se em "estudo profundos sobre a evolução física, moral e intelectual da criança, nos quais a pedagogia experimental vinha-se firmando brilhantemente [...]. A psicologia moderna fornecia as regras diretoras da escola nova: fazer agir a criança; ocupá-la em trabalhos cuja utilidade ela sinta; despertar o interesse a fixar a atenção, partindo sempre do conhecido para o desconhecido, do fácil para o difícil, encadeando observações ate a descoberta de um principio e a verificação ulterior das aplicações desse princípio inconscientemente já feitas. (Carvalho, 1998, p. 228)

Também a Psicologia contribuiu para a renovação escolar, com técnicas educacionais que modificavam o comportamento e a experiência do educando, as quais Campos acatou, do contrário não teria criado a cadeira de Psicologia Educacional no curso normal, pois para ele

representa uma necessidade imperiosa, cuja satisfação vem integrar o curso normal de uma disciplina indispensável á formação da mentalidade do professor primário a psychologia, não apenas a psychologia geral, mas a psychologia educacional, constitui parte indispensável ao equipamento intellectual do professor primário. Certamente, com Ella, os que forem providos de dons especiaes, terão, com esses dons accrescidos pela sciencia e aquelles que forem cegos da intuição terão, com Ella, de certo modo, supprida a sua cegueira. (Campos, 1930, p. 62)

A defesa de Campos da recorrência a áreas da ciência que pudessem dar aporte à educação se fundava no que ele via como uma organização a poderosa: a indústria. Para ele o conhecimento da organização racional do trabalho e da organização de técnicas industriais havia surgido da rotina, das práticas, dos hábitos, da repetição de processos industriais. Nesse caso, a escola como espaço de assimilação da moral, do saber e dos costumes vigentes supunha uma disciplina do corpo e do espírito dos alunos que pudessem torná-los compatíveis com o universo fabril. O Discurso de agradecimento, no banquete oferecido pelas classes intellectuaes de Bello Horizonte - 22 de outubro de 1926 mostra o quanto Campos estava alinhado ao processo de industrialização do país. Para ele, o desenvolvimento e a modernização se vinculavam à organização econômica, industrial e comercial, que garantiria a atividade social e política do país: 
Um paiz sem organização industrial e comercial, com toda a sua majestade, as suas dragonas, os seus parlamentos, as suas declarações de direitos, não passará de um embryão nacional, com uma vida de relação inteiramente artificial e inconsistente por insufficiencia dos seus órgão de nutrição. Até aqui temos cuidado mais de nossa vida de relação do que da nossa vida de nutrição. Começamos a nos apparelhar agora para as duras competições próprias do cyclo de civilização e de cultura dos nossos dias, dirigindo a nossa attenção para os difficeis problemas de organização econômica, industrial e commercial - de maneira a garantir ao mercado nacional as condições indispensáveis á sua efficiencia como órgão destinado a manter e assegurar a nossa actividade social e política, ate agora desapercebidas de uma base physica proporcional á grandeza e extensão do nosso aparelho político. [...] Ora, nós não podemos enriquecer como nação, si o nosso commercio não se acha sufficientemente apparelhado para exercer a sua funcção de colletor e distribuidor, da maneira mais remuneradora possível, das riquezas e da producção do paiz. (Campos, 1930, p. 87)

Era preciso modificar a prática da escola, seus processos, seus mecanismos, seus hábitos para adaptá-la às necessidades do mundo contemporâneo: científicas, de produção, profissionais e culturais. O argumento de Campos pró-renovação educacional se apoiava na ideia de que a escola que propunha era a escola dos países mais avançados no processo de industrialização ou modernização: países europeus como Alemanha, Inglaterra, Bélgica, além dos Estados Unidos. Assim, se a incorporação dos benefícios da civilização - concepções e métodos educacionais de fora - ajudaria a escola a cumprir seu papel de partícipe do desenvolvimento do país, também seria um modo de disciplinar a "densa e compacta massa de analphabetos" para transformá-lo em "instrumentos de producção de bens econômicos e espirituaes", sujeitos ao controle e à disciplina próprios do espaço de produção industrial; isso era exigência urgente "da nossa vocação democrática" (Campos, 1930, p. 71).

Essa campanha pela melhoria da educação escolar, de renovação de concepções, modelos e métodos para a escola continha intenções politiqueiras, como se pode ler nesta passagem do discurso de instalação do Congresso de Instrução, em 8 de maio de 1927:

O futuro das instituições democráticas depende, sobretudo, da orientação e do incremento do ensino primário. [...] Não basta, pois, difundir o ensino primário para dilatar os limites da cidade. Si este ensino não forma homens, não orienta a intelligencia e não distila o senso commum, que é o eixo em torno do qual se organiza a personalidade humana, poderá fazer eleitores, não terá feito cidadãos. (Campos, 1930, p. 101)

Campos sugere que a qualidade da educação escolar era mais importante que sua difusão, isto é, que a quantidade de escolas. Essa possibilidade contradiz, porém, o discurso de seu governo, que vai contra a multiplicação de escolas propalada nos discursos presidenciais do Estado de Minas Gerais, como se lê nesta passagem:

Convergi para a educação publica toda a minha attenção. Fiz della a preoccupação dominante de meu governo. Concentrei nella o melhor dos meus esforços. Reformei o ensino normal e primário. Fundei dezenove escolas normaes e refundi, de todo em todo, as duas únicas escolas normaes officiais existentes. Creei e installei 3.662 escolas primarias, o 
que quer dizer que foram multiplicadas por três as escolas que encontrei. Fundei e installei quatro gymnasios. (Campos, 1930, p. 236)

Dito isso, não podemos negar que o discurso de Campos relativo à renovação educacional em Minas Gerais não convergisse para modernização do Estado. Mas essa convergência não ficou isenta das contradições que marcaram o processo modernizador em Minas Gerais e no Brasil. Os exemplos de seu discurso permitem afirmar essa contradição. Embora insistisse na qualidade da educação, o governo Antônio Carlos enfatizou o dado quantitativo: apresentou a quantidade não só em números exatos - 3.662 -, mas também em proporções - três vezes mais. Além disso, a concepção de educação, de criança e dos fins da escola sugere que ele contribuiu para manter a estrutura social vigente: excludente.

Campos via a educação escolar como instrumento de conservação num momento em que a ideia de modernização supunha quebra do conservadorismo, abertura ao novo, ruptura com a tradição. Mais do que isso, na escola, segundo Campos, a liberdade, espontaneidade e naturalidade da criança é cerceada pela assimilação adaptativa e disciplinada de um estado de coisas. Assim, se Campos almejava à modernidade mineira, não ficou ileso aos entraves à modernização uniforme e incisiva de Minas Gerais. A faceta pró-modernização de seu discurso mostra vínculos com a estrutura oligárquica - mais conservadora, mais arcaica.

\section{Considerações finais}

Esta leitura dos discursos de Antônio Carlos e Francisco Campos tentou mostrar os vínculos desses dois políticos e de seu programa de governo com o projeto de modernização de Minas Gerais pela via da educação. Essa possibilidade compunha o ideário nacional de modernização da sociedade, mas tinha algo de utópico, visto que educar o povo tinha profundo de fazer a massa aderir, sobretudo pelo voto, ao regime republicano e o que ele trazia a reboque: industrialização, controle social e democracia.

Esse discurso educacional modernizante na década de 1920 foi uma forma de projetar Francisco Campos e Antônio Carlos na elite política nacional. Seu projeto político desenvolvido e a dimensão alcançada pela reforma educacional os alçaram à condição de homens prestigiados na intelectualidade e elite dirigente, nas quais ocuparam posições de destaque. Mas se a elaboração interna coerente de sua proposta política garantiu futuro para suas ideias no cenário nacional, isso não bastou para concretizar o projeto de modernização e democratização no Estado em seu conjunto. Os entraves à modernização de Minas Gerais como processo político advinham justamente das formações oligárquicas que sustentavam o programa do governo Antônio Carlos, para as quais modernização significava democratizar - assegurar o direito de voto e angariar eleitores - para proteger seus bens e aumentá-los.

Se o debate sobre a escolarização era próprio dos círculos de intelectuais, nos anos 1920 ele cooptou novos debatedores: os políticos. Assim, estes e aqueles, fossem intelectuais-políticos ou políticos-intelectuais, viram a escola como vetor de democratização com cidadania. O resultado foi a imbricação do discurso educacional com o discurso político, em que a política passaria a traçar os rumos da educação. Essa articulação pode ser vista, tanto como uma tentativa de fazer o país se desenvolver com base na educação escolar, quanto o desejo de construir uma nação democrática e com 
cidadania pela educação. Mas essa intenção, muitas vezes, esbarrou na vontade política e se mostrou em doses controladas, na medida das necessidades e dos interesses da classe dominante. Assim, o movimento de construção do regime de governo republicano foi intrínseco aos movimentos de construção dos projetos de educação elaborados para produzir a República.

Percebemos, porém, que muitas vezes tais reformas deixavam a desejar em modificações mais profundas e significativas no sistema de ensino, assim como se distanciaram, na prática, das propostas expostas e defendidas discursivamente. Por isso, foram vistas como fragmentadas, desarticuladas, parciais, arbitrárias, lançadas sem solidez econômica e sem visão global do problema. Nesse contexto de mudanças e discussões sobre a instrução pública como fator de modernização do país, insere-se a Reforma Educacional Francisco Campos. Atentos às mudanças e perspectivas no ensino primário nacional e estadual, seus idealizadores - Antônio Carlos, então presidente de Minas Gerais, e Francisco Campos, secretário do Interior - esforçaram-se para promover melhorias na educação como forma de consolidar o progresso e a modernização do Estado.

Sua finalidade era instituir uma política educacional segundo princípios e bases modernos. Dizia-se que era necessária e que deveria começar pela instrução primária, mais útil à massa de cidadãos porque o país só se desenvolveria e se modernizaria pela escola, que deveria capacitá-los a entender seus direitos e seus deveres. Ao difundirem a escola primária, visualizavam a possibilidade de controle, fundamental à formação do país e de seu povo.

Embora a reforma se vinculasse ao objetivo de modernizar o Estado mineiro, este estudo aponta que ela foi parcial, pois a modernização não dependia só da escola, mas também de mudanças nos contextos sociais e na mentalidade da população. Sobretudo, talvez porque os ideais de modernidade difundidos sempre se misturaram com elementos de uma sociedade tradicional, conservadora, agrário-exportadora, oligárquica e cuja maioria da população residia no campo. Mesmo com as transformações que a República propôs em Minas Gerais, não democratizaram os direitos políticos, seu principal objetivo.

Isso nos fez acreditar que o governo de Antônio Carlos desenvolveu a reforma Francisco Campos como marco modernizador de uma ação conservadora coerente com a perspectiva transformadora que então se propunha na República. Num segundo momento, a pesquisa mostrou que ele e Campos, a fim de consolidar seu projeto político, modernizar Minas Gerais, assumem ideologicamente ideais vistos como liberais: assegurar o exercício livre e tranquilo do voto e assegurar liberdades públicas e um Estado analfabeto, oligárquico e autoritário. A feição moderna desses ideais não ocultava seus traços do conservadorismo que então marcava a sociedade mineira: via-se a escola como mecanismo de poder pelo qual se poderia inculcar os princípios liberais nas novas gerações para garantir a consolidação e continuidade da ordem.

Além disso, Francisco Campos e Antônio Carlos representavam os interesses das elites dirigentes que buscavam consolidar a modernidade em Minas Gerais. Conservadoras, tais elites diziam que buscavam a democracia, mas esta não devia pôr em risco a manutenção de privilégios daquelas, por isso mantinham seus interesses reproduzindo o modelo de exclusão política. Eis por que se pode ver o projeto educacional desses dois políticos como busca de uma democracia aparente, afinal, não 
lograram disseminar a instrução pública de modo que o trabalhador pudesse ampliar sua participação política via escolarização nem facilitar a participação política democrática.

A Reforma Francisco Campos apresentou limites, sobretudo em sua incorporação de ideais de modernização em prol da educação mineira do decênio de 1920. Um deles foi a introdução dos princípios da Escola Nova via importação de ideias relativas ao ensino em nações mais desenvolvidas da Europa e da América do Norte. As especificidades econômicas, sociais, culturais, políticas e pedagógicas do Brasil e de seu povo foram desconsideradas, se não no todo, ao menos em parte. Outro limite foi a legislação, que por si só não basta para modificar a educação nem a mentalidade da sociedade mineira; tal mudança dependia de condições básicas de desenvolvimento de toda a sociedade, as quais muitas vezes eram precárias graças à falta de recursos materiais e humanos para formação educacional.

A essas limitações se acresce a lentidão na substituição de concepções antigas da escola dita tradicional por concepções tidas como mais modernas - da escola nova. Perduram métodos antigos porque a proposta não se efetivou no Estado todo e chegou só a uma parcela da população. Por fim, também limitante é a organização pedagógica subordinada aos poderes políticos, por não possibilitar o desenvolvimento de princípios básicos pertinentes ao movimento da escola nova como a liberdade, a cidadania e a democracia. A busca por tais princípios não resultou de construção coletiva, mas de imposição do poder.

\section{Referências}

ABREU, Alzira Alves de (coord.). Dicionário histórico-biográfico brasileiro pós-1930. Rio de Janeiro: FGV/CPDOC, 2001.

CAMPOS, Francisco Luis da Silva. Pela civilização mineira. Belo Horizonte: Imprensa Oficial, 1930.

CARVALHO, Marta Maria Chagas. Molde nacional e fôrma cívica: higiene, moral e trabalho no projeto da Associação Brasileira de Educação. Bragança Paulista: USF, 1998.

DAHLBERG, Gunilla; MOSS, Peter; PENCE. Alan. Qualidade na educação infantil da primeira infância: perspectivas pós-modernas. Porto Alegre: Artmed, 2003.

HABERMAS, Jürgen. O discurso filosófico da modernidade. Lisboa: Dom Quixote, 1990.

INSTITUTO BRASILEIRO DE GEORGRAFIA E ESTATISTICA. Tendências demográficas: uma análise dos resultados do universo do censo demográfico de 2000 . Rio de Janeiro: IBGE, 2002.

LE GOFF, Jacques. Antigo/moderno. Enciclopédia Einaudi. Porto: Imprensa Nacional Casa da Moeda, 1984.

MACHADO, Maria Cristina Gomes. O projeto Rui Barbosa: o papel da educação na modernização da sociedade. Disponível em: <http://www.casaruibarbosa.gov.br/dados/ DOC/artigos/a-j/FCRB_MariaCristina_Projeto_RuiBarbosa.pdf $>$. Acesso em: 19 set., 2009.

MINAS GERAIS. Mensagem presidencial do presidente Antônio Carlos Ribeiro de Andrada dirigida ao Plenário em 1927a. In: Arquivo Público Mineiro/APM. Relatórios de mensagens do governo mineiro - mensagens presidenciais de Antônio Carlos Ribeiro de Andrada. Filme 5 e 6, gaveta B1. 
MINAS GERAIS. Mensagem presidencial do presidente Antônio Carlos Ribeiro de Andrada dirigida ao Plenário em 1927b. In: Arquivo Público Mineiro/APM. Relatórios de mensagens do governo mineiro - mensagens presidenciais de Antônio Carlos Ribeiro de Andrada. Filme 5 e 6, gaveta B1.

MINAS GERAIS. Mensagem presidencial do presidente Antônio Carlos Ribeiro de Andrada dirigida ao Plenário em 1928. In: Arquivo Público Mineiro/APM. Relatórios de mensagens do governo mineiro - mensagens presidenciais de Antônio Carlos Ribeiro de Andrada. Filme 5 e 6, gaveta B1.

MORAES, Maria Célia Marcondes. Reformas do ensino, modernização administrada: a experiência de Francisco Campos (anos 20 e 30). Florianópolis: UFSC, 2000.

NAGLE, Jorge. Educação e sociedade na primeira república. Rio de Janeiro: DP\&A, 2001.

OLIVEIRA, Itamar de. Francisco Campos: a inteligência no poder. Recife: Libertas, 1996.

PAIM, Antônio. História das idéias filosóficas no Brasil. São Paulo: Fundação Nacional Pró-memória, 1984.

PAIM, Antonio. História do liberalismo brasileiro. São Paulo: Mandarim, 1998.

PAIM, Antonio. O liberalismo contemporâneo. Rio de Janeiro: Tempo Brasileiro, 2000.

PAULA, João Antonio. Raízes da modernidade em Minas Gerais. Belo Horizonte: Autêntica, 2000.

PÉCAUT, Daniel. Os intelectuais e a política no Brasil: entre o povo e a nação. São Paulo: Ática, 1990.

PEIXOTO, Anamaria Casasanta. Educação no Brasil: anos vinte. São Paulo: Loyola, 1983.

PINHEIRO, Paulo Sérgio. Classes médias urbanas: formação, natureza, intervenção na vida política. In: Boris Fausto (org.). História geral da civilização brasileira: o Brasil republicano; tomo III: sociedade e instituições (1889-1930). Rio de Janeiro: Bertrand Brasil, 1997, p. 9-51.

RODRIGUES, Almerinda M. R. V. O movimento da escola nova no sul de Mato Grosso: uma análise de suas contribuições para a educação do Estado na primeira metade do século 20. Dourados: UFMS, 2006. 144f. Dissertação (mestrado em História). Universidade Federal do Mato Grosso do Sul.

VALDEMARIM, Vera Teresa. História dos métodos e materiais de ensino: a escola nova e seus modos de uso. São Paulo: Cortez, 2010.

VIDAL, Diana Gonçalves. Modernismos, modernidades e educação: o lugar dos intelectuais no Brasil dos anos 1930. In: VAGO, Tarcísio Mauro et al (org.). Intelectuais e escola pública no Brasil: séculos 19 e 20. Belo Horizonte: Mazza, 2009, p. 121-145.

WIRTH, John D. O fiel da balança: Minas Gerais na federação brasileira. Rio de Janeiro: Paz e Terra, 1982. 
PÂMELA FARIA OLIVEIRA é mestre em Educação pelo Programa de Pós-Graduação em Educação da Universidade Federal de Uberlândia. Professora na Escola de Educação Básica da Universidade Federal de Uberlândia.

Endereço: Av. Brasil, 509 - 38405-312 - Uberlândia - MG - Brasil.

E-mail: pamela8oliveira@hotmail.com.

CARLOS HENRIQUE DE CARVALHO é doutor em História pela Universidade de São Paulo. Professor na Faculdade de Educação e no Programa de Pós-Graduação em Educação da Universidade Federal de Uberlândia.

Endereço: Rua Aracaju, 201 - 38401-254 - Uberlândia - MG - Brasil.

E-mail: carloshcarvalho06@yahoo.com.br.

Recebido em 24 de novembro de 2012.

Aceito em 19 de setembro de 2013. 